\title{
La criminalización de la protesta: el caso Norín Catrimán y otros (Dirigentes, miembros y activista del pueblo indígena Mapuche) vs. Chile \\ Criminalization of protest: Norín Catrimán et al. (Leaders, members and activist of the Mapuche indigenous people) v. Chile case
}

\author{
Sebastián Becker Castellaro* \\ Universidad de Chile, Chile \\ Abogado. Licenciado en Ciencias Jurídicas y Sociales, Universidad de Chile. Ayudante ad honorem del Departamento \\ de Derecho Público, Facultad de Derecho Universidad de Chile. \\ sebastian.becker.castellaro@gmail.com
}

\section{RESUMEN}

Este trabajo realiza una sistematización sobre qué derechos humanos fueron vulnerados por el Estado chileno en el caso Lonkos vs. Chile, comprobando que en ellas subyace una noción de criminalización de la protesta que atenta no solo contra los derechos humanos de los líderes mapuches involucrados, sino además contra la democracia interna del Estado chileno.

Palabras clave: Presunción de inocencia - Estado democrático de Derecho - conflicto mapuche criminalización de la protesta.

\begin{abstract}
This paper reviews systematically which human rights were violated by the Chilean state in the Lonkos v. Chile case, confirming a notion of criminalization of protest underlies, affecting not only the human rights of the Mapuche leaders involved, but also the internal democracy of the Chilean state.
\end{abstract}

Key words: Presumption of innocence - Rule of Law - Mapuche conflict - criminalization of protest.

\section{Introducción}

El año 2014 la Corte Interamericana de Derechos Humanos (Corte IDH) condenó al Estado de Chile en el caso "Norín Catrimán y otros" ${ }^{1}$ por la violación de derechos humanos en contra de comuneros mapuches. El caso presenta diversas aristas de las cuales el presente trabajo pretende revisar cómo se gestó la criminalización de la protesta mapuche, y analizar qué vulneraciones a derechos humanos se produjeron para configurar tal criminalización.

\section{Contexto}

Entre 2001 y 2002 se abrieron procesos penales en contra de los señores Segundo Aniceto Norín Catrimán, Pascual Huentequeo Pichún Paillalao, Víctor Manuel Ancalaf Llaupe, Juan Ciriaco

\footnotetext{
* Agradezco los comentarios de Natalia Arévalo que me ayudaron a clarificar pasajes oscuros del texto inicial, y a Magdalena Bordagorry por su rigurosidad en las correcciones; naturalmente, los errores son a título personal.

1 Corte IDH. Caso Norín Catrimán y otros (Dirigentes, miembros y activista del pueblo indígena Mapuche) vs. Chile. Fondo, Reparaciones y Costas. Sentencia de 29 de mayo de 2014. Serie C No. 279.
} 
Millacheo Licán, Florencio Jaime Marileo Saravia, José Benicio Huenchunao Mariñán, Juan Patricio Marileo Saravia y la señora Patricia Roxana Troncoso Robles, todos ellos activistas de la etnia mapuche por delitos de terrorismo.

Tales procesos penales vienen enmarcados por un contexto histórico y político de reivindicaciones culturales y territoriales del Pueblo Mapuche contra el Estado chileno. Los antecedentes históricos señalan que el "proceso de integración [mapuches y Estado de Chile] desde la mal Ilamada 'pacificación de la Araucanía' hasta la dictadura y aun hasta hoy en día, ha significado el ejercicio de cierta violencia, ya sea simbólica o física -'Por la razón o la fuerza'-, de parte del Estado chileno ${ }^{2 \prime}$. Por ejemplo, se ha señalado que la disputa sobre territorios mapuches proviene de finales del siglo XIX debido a traspasos de tierras (títulos de merced) a propietarios privados, mayormente territorio Mapuche en La Araucanía, siendo estos relegados a una ínfima parte de sus terrenos ${ }^{3}$. Expertos señalan que se otorgaron 3000 parcelas -un total de 510.000 hectáreas- siendo un 6,4\% de su territorio original ${ }^{4}$. Asimismo, "la política de restitución iniciada en décadas recientes es claramente insuficiente y no ha logrado revertir la grave situación de pobreza y marginalidad en que se encuentra el Pueblo Mapuche, ni impedir el rápido proceso de desintegración cultural y deterioro de la tierra ${ }^{5 \prime}$. Esto ha sido calificado por algunos académicos como una exclusión del Pueblo Mapuche al pacto político, teniendo como consecuencia que el Pueblo Mapuche "ha decidido abandonar el derecho, a pesar de 'la inclusión' que le da formalmente la ley indígena a través de esta modalidad de Pacto Social 'Republicano', lo cierto es que forman parte de los 'excluidos' por su forma de vida y pertenecer a una etnia distinta" 6 . Por la misma razón, ante "la marginalidad y la exclusión, la imposibilidad de encontrar respuestas en la institucionalidad, dan lugar a movilizaciones más radicales que, a su vez, son contenidas con represión policial, lo cual va detonando una espiral de violencia que potencia la referida criminalización de la demanda indígena ${ }^{7 \prime \prime}$.

Una manifestación de lo anterior es el aparato de persecución penal del Estado, el Ministerio Público ha incluido dentro de sus políticas criminales la etiqueta de conflicto mapuche, definiéndola como aquella que:

"[S]e produce en el contexto o con la finalidad de recuperar o reivindicar, usualmente
por medios violentos, terrenos sobre los cuales se alegan derechos territoriales, de pro-
piedad, ancestrales del Pueblo Mapuche; o para reivindicar otros derechos que también
la etnia mapuche alega privación o lesión, por ejemplo, derechos relacionados con el

2 MELLA, Eduardo y LE BONNIEC, Fabien. Movimiento mapuche y justicia chilena en la actualidad: reflexiones acerca de la judicialización de las reivindicaciones mapuches en Chile. Derechos Humanos y pueblos indígenas: tendencias internacionales y contexto chileno, Instituto de Estudios Indígenas. Temuco, Universidad de La Frontera, 2004. pp. 355356. Agregado "mapuches y Estado de Chile" es propio.

3 COUSO SALAS, Jaime. Mapuches y Derecho penal. En: OLEA, Helena (Ed.). Derecho y Pueblo Mapuche. Santiago, Centro de Derechos Humanos, Universidad Diego Portales, 2013, p. 164.

4 RICHARDS, Patricia y PARK, Yun-Joo. Negotiating Neoliberal Multiculturalism: Mapuche Workers in the Chilean State. Social Forces, 3(85): 1319-1339, 2007, p. 1321.

5 COUSO SALAS, Jaime. Mapuches y derecho penal... op. cit., p. 164.

6 VILLEGAS, Myrna. El Derecho penal del enemigo y la criminalización del Pueblo Mapuche. Foro N-OR Working Paper 01/2007, Universidad Católica del Norte, p. 25. Disponible [en línea] <http://es.scribd.com/doc/7295665/VillegasMyrna-El-Derecho-Penal-Del-Enemigo-y-LaCriminalizacion-Del Pueblo-Mapuche> [Consulta: 24 de enero de 2015].

7 FAUNDES PEÑAFIEL, Juan Jorge. Integración regional, reformas a la justicia y respeto del estándar internacional de derechos humanos en los procesos penales seguidos contra indígenas movilizados socialmente. En: ÁLVAREZ, Mario y CIPPITANI, Roberto. Derechos Individuales e Integración Regional (Antología). Ciudad de México, Instituto Tecnológico y de Estudios Superiores de Monterrey - Campus de Ciudad de México, 2013. p. 436. 
medioambiente; como también cuando los sucesos tienen por finalidad el rechazo de decisiones de autoridad en relación a la reivindicación de derechos aludida precedentemente ${ }^{8 \prime}$.

Cabe señalar además que a partir del 2001 se incrementó significativamente el número de miembros mapuches investigados y juzgados por delitos penales. Según datos del Ministerio Público, entre 2008 y 2012 se han investigado 843 presuntos delitos cometidos por personas mapuches en La Araucanía en el marco del "conflicto mapuche" ${ }^{\prime 9}$. Según los mismos datos entregados a la Corte IDH, entre el 2000 y el 2013 el Ministerio Público ha formalizado 19 causas terroristas de las cuales 12 se relacionan con el "conflicto mapuche"10.

Así, el contexto de los juicios penales del Estado de Chile contra los dirigentes mapuches no es pacífico; este proviene de un conflicto histórico desde la colonización, siendo este "uno de los problemas históricos más graves que afectan a los pueblos indígenas en Chile ${ }^{11 " ;}$ que en los últimos ha dinamizado en una vinculación estereotipada de la violencia con el Pueblo Mapuche, considerando la Corte IDH, que tales etiquetas "deslegitiman la reivindicación de los derechos territoriales del Pueblo Indígena Mapuche o califican su protesta social de forma generalizada como violenta o la presentan como generadora de un conflicto entre dicho pueblo y el resto de la población de la zona ${ }^{12 "}$.

\section{Procesos penales}

\subsection{Juicios contra Norín Catrimán, Pichún Paillalao y Troncoso Robles}

A los señores Segundo Aniceto Norín Catrimán y Pascual Huentequeo Pichún Paillalao, Lonkos de las comunidades "Lorenzo Norín" de Didaico y "Antonio Ñirripil" de Telememu, respectivamente, y a la señora Troncoso Robles fueron investigados penalmente por los siguientes delitos:

i) Tres delitos de "incendio terrorista" por hechos ocurridos el 12 de diciembre y 16 de diciembre del 2001 y otro "durante el año 2001"13" y;

ii) delito de "amenazas de incendio terrorista" de quemar el predio Nancahue ocurridas "durante el año 2001"14;

Luego de dos juicios, el primero anulado por la Corte Suprema que había absuelto a los líderes mapuches, el Tribunal de Juicio Oral en lo Penal de Angol (TJOP de Angol) sentenció que respecto de Patricia Troncoso "no concurrió ningún antecedente directo que [la] vincule con una posible autoría de los delitos por las cuales fue acusada ${ }^{15}$ ". Respecto de Pichún Paillalao y Norín Catrimán, ambos fueron condenados por los delitos de amenazas de incendio terrorista, aplicándose la

8 MINISTERIO PÚBLICO, Oficio FN No. 319-2013, 13 de mayo de 2013. En: INSTITUTO NACIONAL DE DERECHOS HUMANOS. Estudio exploratorio. Estado de Chile y Pueblo Mapuche: Análisis de tendencias en materia de violencia estatal en la región de la Araucanía. Santiago, INDH, 2014. p. 17. El destacado es propio.

9 Ibídem.

10 Corte IDH. Caso Norín Catrimán y otros (Dirigentes, miembros y activista del pueblo indígena Mapuche) vs. Chile. Fondo, Reparaciones y Costas. Sentencia de 29 de mayo de 2014. Serie C No. 279, párr. 217.

11 CENTRO DE DERECHOS HUMANOS. Informe anual sobre Derechos Humanos en Chile 2014, Santiago, Universidad Diego Portales, 2014. p. 161.

12 Corte IDH. Caso Norín Catrimán y otros (Dirigentes, miembros y activista del pueblo indígena Mapuche) vs. Chile, op. cit., párr. 93.

13 Ibídem, párr. 106.

14 Ibídem.

15 Ibídem, párr. 116. 
presunción legal de intención de infundir temor en la población del artículo $1^{\circ}$ número $1^{\circ}$ inciso segundo de la Ley Antiterrorista (Ley 18.314) ${ }^{16}$; además a Pichún Paillalao y a Norín Catrimán se los condenó como autores del delito de amenazas terroristas. Las penas para ambos fueron:

i) Cinco años y un día de presidio mayor en su grado mínimo, y las penas accesorias de "inhabilitación absoluta perpetua para cargos y oficios públicos y derechos políticos y la de inhabilitación absoluta para profesiones titulares mientras dure la condena";

ii) Las penas accesorias de "inhabilita[ción] por el plazo de quince años para ejercer funciones o cargos públicos, sean o no de elección popular, o de rector o director de establecimiento de educación, o para ejercer en ellos funciones de enseñanza; para explotar un medio de comunicación social o ser director o administrador del mismo, o para desempeñar en él funciones relacionadas con la emisión o difusión de opiniones o informaciones; ni podrán ser dirigentes de organizaciones políticas o relacionadas con la educación o de carácter vecinal, profesional, empresarial, sindical, estudiantil o gremial en general, durante dicho plazo"17.

\subsection{Proceso contra Juan Patricio Marileo Saravia, Florencio Jaime Marileo Saravia, José Benicio Huenchunao Mariñán, Juan Ciriaco Millacheo Licán y Patricia Roxana Troncoso Robles}

Con fecha 22 de agosto de 2004 el TJOP de Angol declaró culpables a las víctimas individualizadas arriba por el delito de incendio terrorista ocurrido el 19 de diciembre del 2001. La pena fue de "diez años y un día de presidio mayor en su grado medio y las penas accesorias de 'inhabilitación absoluta perpetua para cargos y oficios públicos y derechos políticos e inhabilitación absoluta para profesiones titulares mientras dure la condena'18".

Individualmente las víctimas interpusieron recurso de nulidad frente a la sentencia condenatoria, solicitando la anulación del juicio, para la posterior realización de uno nuevo, y, en subsidio, que se anulara la sentencia y se dictará otra en reemplazo, desestimando el carácter terrorista del delito. La Corte de Apelaciones de Temuco, con fecha 13 de octubre de 2004, desestimó los recursos de nulidad manteniendo la sentencia condenatoria.

16 Señalaba la Ley № 18.314 el año 2003: Artículo $1^{\circ}$.- Constituirán delitos de terrorismo los enumerados en el artículo $2^{\circ}$, cuando en ellos concurriere alguna de las circunstancias siguientes: 1 a Que el delito se cometa con la finalidad de producir en la población o en una parte de ella el temor justificado de ser víctima de delitos de la misma especie, sea por la naturaleza y efectos de los medios empleados, sea por la evidencia de que obedece a un plan premeditado de atentar contra una categoría o grupo determinado de personas. Se presumirá la finalidad de producir dicho temor en la población en general, salvo que conste lo contrario, por el hecho de cometerse el delito mediante artificios explosivos o incendiarios, armas de gran poder destructivo, medios tóxicos, corrosivos o infecciosos u otros que pudieren ocasionar grandes estragos, o mediante el envío de cartas, paquetes u objetos similares, de efectos explosivos o tóxicos. Cabe señalar que en 2010, mediante la Ley 20.467, se deroga la presunción del dolo terrorista. No es necesario indicar la fuente de la ley, pues se presume conocida.

17 Corte IDH. Caso Norín Catrimán y otros (Dirigentes, miembros y activista del pueblo indígena Mapuche) vs. Chile, op. cit., párr. 117.

18 Ibídem, párr. 126. 


\subsection{Proceso en contra de Víctor Manuel Ancalaf Llaupe ${ }^{19}$}

Al señor Ancalaf Llaupe se le imputaron los siguientes delitos: autor del "delito de terrorismo contemplado en el artículo $2^{\circ} \mathrm{N}^{\circ} 4^{20}$ de la Ley $\mathrm{N}^{\circ} 18.314$, en relación con el artículo $1^{\circ}$ del mismo texto legal", por la quema de cuatro camiones de distintas empresas entre los años 2001 y $2002^{21}$, siendo condenado por la Corte de Apelaciones de Concepción como autor de dichos delitos de terrorismo.

Frente a la condena se interpuso recurso de apelación ante la misma Corte de Apelaciones de Concepción fallando esta que:

i) Revoca condena de 10 años y un día por los delitos de terrorismo cometidos el día 29 de septiembre de 2001 y 3 de marzo de 2002, absolviendo de dichos cargos formulados en la acusación.

ii) Confirma sentencia únicamente como autor del delito de terrorismo cometido el 17 de marzo de 2002, condenándolo a una pena de cinco años y un día de presidio mayor en su grado mínimo 22 .

A pesar de esta supuesta revocación parcial, la Corte IDH hizo una salvedad: en virtud de la declaración que el señor Ancalaf Llaupe realizó en la audiencia pública celebrada en la Corte $\mathrm{IDH}^{23}$, ella entiende que "la sentencia de la Corte de Apelaciones de Concepción confirmó las penas accesorias establecidas en el fallo de primera instancia ${ }^{24 " .}$

\section{La criminalización de la protesta del Estado de Chile contra comuneros mapuches}

Para poder desarrollar la criminalización de la protesta se utilizará, entre otros autores, la idea de Estado democrático de Derecho de Jürgen Habermas, en cuanto esta comprende "una empresa siempre sujeta a riesgos, irritable e incitable, y sobre todo falible y necesitada de revisión, empresa que se endereza a realizar siempre de nuevo y en circunstancias cambiantes el sistema de los derechos, es decir, a interpretarlo mejor, a institucionalizarlo en términos más adecuados, y a hacer uso de su contenido de forma más radical ${ }^{25}$. Esto quiere decir que en democracia se exige-permite repensar, replantear y tomar postura sobre la legitimidad del Estado de Derecho. Ello solo es posible por medio de un aseguramiento a los ciudadanos de derechos fundamentales. Por consiguiente, las violaciones de derechos humanos del Estado chileno, que denunciaron las víctimas del caso, y que se analizan a continuación, criminalizaron la protesta porque el Estado

19 En virtud de la fecha en la cual supuestamente ocurrieron los hechos el señor Ancalaf se rige por el Código de Procedimiento Penal de 1906 y no por el Código Procesal Penal de 2000.

20 Ley $N^{\circ}$ 18.314, Ministerio del Interior. Santiago de Chile, Mayo 1984. Artículo $2^{\circ}$.- Constituirán delitos terroristas, cuando reunieren alguna de las características señaladas en el artículo anterior: $\mathrm{n}^{\circ} 4$ Colocar, lanzar o disparar bombas o artefactos explosivos o incendiarios de cualquier tipo, que afecten o puedan afectar la integridad física de personas o causar daño.

21 Corte IDH. Caso Norín Catrimán y otros (Dirigentes, miembros y activista del pueblo indígena Mapuche) vs. Chile, op. cit., párr. 133.

22 Ibídem, párr. 147.

23 Ancalaf Llaupe declaró: "Yo he quedado por ejemplo de por vida sin poder ejercer cargos públicos, no he podido ejercer el derecho cívico de dirigir algún directorio en alguna determinada empresa, o en este caso asumir cargos en algún municipio o en cualquiera otro organismo del Estado". En: Ibídem, párr. 148.

24 Corte IDH. Caso Norín Catrimán y otros (Dirigentes, miembros y activista del pueblo indígena Mapuche) vs. Chile, op. cit., párr. 135.

25 HABERMAS, Jürgen. Facticidad y Validez. $5^{\circ}$ Edición. Madrid, Trotta, 2008, p. 466. 
cortó los discursos políticos que fluyen en una sociedad por medio de la judicialización penal -y sus sentencias- de reivindicaciones mapuches ya mencionadas en el acápite "contexto".

En el caso concreto, la criminalización de la protesta, a pesar de las múltiples veces que se menciona en la sentencia, no se establece como una violación per se en la Convención Americana de Derechos Humanos (CADH). No obstante, la protesta corresponde a una exteriorización de varios derechos constitucionales (libertad de expresión, conciencia, derecho a reunión, etcétera) por lo que jamás puede ser configurada como delito ${ }^{26}$. Asimismo es que, frente a hechos antijurídicos enmarcados en protestas sociales, deben buscarse todas las vías jurídicas posibles antes que aplicar la última ratio del derecho: el derecho punitivo ${ }^{27}$.

Entonces, la criminalización de la protesta se configuró por el Estado de Chile, "como entramados o estrategias de desarticulación que incluyen la represión sobre quienes no aceptan someterse a las políticas estatales ${ }^{28 \prime}$. Los apartados siguientes sistematizarán las violaciones de derechos humanos que concurrieron en el caso, explicando el porqué de la criminalización.

\section{Aplicación de la Ley Antiterrorista, discriminación y violación a la presunción de inocencia}

En el acápite "contexto" señalamos que la aplicación de la Ley 18.314 ha tenido como principal sujeto pasivo a miembros de la comunidad mapuche. Sin embargo, la Corte IDH entendió que en este caso no hubo una aplicación "selectiva" de carácter discriminatorio ${ }^{29}$, debido a que no fueron aportados elementos suficientes que permitan entender que la aplicación de la Ley Antiterrorista fuese especialmente distinta para personas de la etnia mapuche ${ }^{30}$. No obstante, el voto disidente de los jueces Manuel Ventura y Eduardo Ferrer señala que la aplicación de la Ley Antiterrorista chilena estuvo "basado[s] en estereotipos y prejuicios étnicos negativos, exteriorizan[do] que los juzgadores tuvieron prejuicios personales respecto de los imputados y que fueron decisivos para establecer responsabilidad penal ${ }^{31 "}$. Es decir, para tales jueces hubo un trato discriminatorio a la etnia mapuche violándose el artículo 8.1 de la CADH, en cuanto al derecho de un juez imparcial que garantice la presunción de inocencia de los imputados en los casos penales recién expuestos. Para los jueces disidentes hubo concepciones discriminatorias que atentaron con la presunción de inocencia, materializando un nexo causal "entre el origen mapuche de las presuntas víctimas y la determinación de su responsabilidad penal ${ }^{32 " .}$

En el mismo sentido, hay que recordar que la aplicación de la Ley Antiterrorista en Chile sirvió como dispositivo para reprimir grupos de oposición política ${ }^{33}$, por medio de una tipificación de delitos vagos y amplios, cuya aplicación, según la Corte IDH, "infringe tanto la presunción

26 ZAFFARONI, Eugenio Raúl. Derecho penal y protesta social, En: BERTONI, Eduardo (Comp.). ¿Es legítima la criminalización de la protesta? Derecho Penal y Libertad de expresión en América Latina. $1^{\text {a }}$ Edición. Buenos Aires, Universidad de Palermo, 2010. p. 6.

27 GARGARELLA, Roberto. Derecho a la protesta social. Derecho y Humanidades. (12): 141-151, 2006, p. 150.

28 FAUNDES PEÑAFIEL, Jorge. Integración regional... op. cit. p. 435

29 Corte IDH. Caso Norín Catrimán y otros (Dirigentes, miembros y activista del pueblo indígena Mapuche) vs. Chile, op. cit., párr. 219.

30 lbídem.

31 Ibídem. Voto conjunto disidente de los jueces Manuel E. Ventura Robles y Eduardo Ferrer Mac-Gregor Poisot, párr. 42.

32 Ibídem, párrs. 37 y 39.

33 MEDINA QUIROGA, Cecilia. Derechos Humanos y aplicación de la Ley 18.314, que determina las conductas terroristas y fija su penalidad [Informe en derecho]. Doctrina Procesal Penal, 2012. p. 45. 
de inocencia de estas personas como la prohibición de discriminación ${ }^{34 \prime}$. En este caso, para la profesora Medina, la aplicación de la Ley 18.314 de manera desproporcional y perjudicial sobre comuneros mapuche revela efectos discriminatorios en su aplicación ${ }^{35}$, debido a las consecuencias inherentes de estigmatización que conlleva la aplicación solo a un grupo determinado de personas $^{36}$. Por ello entonces, "la utilización de estereotipos y prejuicios en las sentencias penales internas 37 " no solo sirvió, dictamina la Corte IDH, como una "violación del derecho a un juez o tribunal imparcial ${ }^{38 "}$, sino además un mecanismo de estigmatización al Pueblo Mapuche asociando sus reivindicaciones políticas como necesariamente violentas vulnerando el principio de presunción de inocencia.

\section{Violación a la libertad personal y presunción de inocencia}

La Corte IDH divide en cuatro los fundamentos para declarar que las detenciones y privaciones de libertad de los comuneros mapuches fueron arbitrarias e ilegales ${ }^{39}$. Aquí se sintetizarán los argumentos para poder mostrar cómo se gestó la prisión preventiva y sus fundamentos para justificarla, concluyendo que tales mecanismos también condujeron a una criminalización de la protesta violando, entre otros derechos, la presunción de inocencia.

\subsection{Falta de elementos probatorios}

En el caso señores Norín y Pichún la Corte IDH estableció que se cumplió con este elemento para satisfacer la prisión preventiva ${ }^{40}$, en cuanto a presumir razonablemente que los comuneros mapuches habrían participado en la comisión del delito. Sin embargo, respecto de las demás víctimas, la prisión preventiva "se fundó únicamente en 'declaraciones reservadas', sin exponer

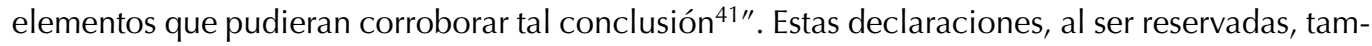
poco pudieron ser controvertidas por la defensa de los comuneros mapuches, y además, no fueron acompañadas de argumentos adicionales que sustentaran la medida cautelar ${ }^{42}$. En consecuencia, sentencia la Corte IDH, no hubo elementos suficientes para demostrar una razonable participación de los delitos investigados, inobservando el estándar en el cual deben "existir indicios suficientes que permitan suponer razonablemente la culpabilidad de la persona sometida a un proceso y que la detención sea estrictamente necesaria para asegurar que el acusado no impedirá el desarrollo eficiente de las investigaciones $(. . .)^{43 \prime \prime}$.

\footnotetext{
34 Ibídem, p. 46

35 Ibídem, p. 47

36 Ibídem.

37 Corte IDH. Caso Norín Catrimán y otros (Dirigentes, miembros y activista del pueblo indígena Mapuche) vs. Chile, op. cit., párr. 222.

38 Ibídem, párr. 229.

39 Véase: Ibídem, párr. 311, y Corte IDH. Caso Chaparro Álvarez y Lapo Iñiguez vs. Ecuador. Excepciones Preliminares, Fondo, Reparaciones y Costas. Sentencia de 21 de noviembre de 2007. Serie C No. 170, párr. 103.

40 Corte IDH. Caso Norín Catrimán y otros (Dirigentes, miembros y activista del pueblo indígena Mapuche) vs. Chile, op. cit., párr. 351.

41 Ibídem, p. 116

42 Ídem.

43 Corte IDH. Caso Servellón García y otros vs. Honduras. Sentencia de 21 de septiembre de 2006. Serie C. No. 152, párr. 90.
} 


\subsection{Falta de fin legítimo}

En todos los casos sucedió lo mismo: las sentencias que dictaminaron la prisión preventiva de las víctimas no fundamentaron cuál era el fin procesal que perseguía esta, sino solo se fundaron en que los imputados eran "un peligro para la seguridad de la sociedad"4" no "acompañado de una explicación sobre cómo ello incidiría en algún riesgo procesal ${ }^{45}$ ". Solo se tuvo en cuenta 'la gravedad del delito investigado', 'antecedentes personales del imputado' y el 'número de delitos investigados' que "no justifican por sí mismos la prisión preventiva y que no fueron valorados en el contexto de la evaluación de la necesidad de la medida en las circunstancias del caso concreto ${ }^{46 \prime}$. Convirtiendo así, la prisión preventiva en una pena punitiva en sí misma y no en una medida cautelar para fines del proceso, afectando su libertad personal y la presunción de inocencia.

\subsection{Inadecuada revisión periódica}

La Corte IDH expresó que un tribunal debe "entender que es tarea del juez analizar si subsisten circunstancias que hagan que la prisión preventiva deba mantenerse y sea una medida proporcional para alcanzar el fin procesal perseguido ${ }^{47 "}$, y en estos casos debió realizarse una revisión motivada que mantuviera la prisión preventiva. Sin embargo, en las justificaciones para mantener la prisión preventiva "no se refirieron a ningún fin procesal ${ }^{48 "}$ ", ni hubo "motivación alguna4" para mantener tales medidas.

\subsection{Presunción de inocencia}

En virtud de los tres argumentos recién expuestos es que las víctimas recién nombradas "tenían derecho a que se les presumiera inocentes ${ }^{50 "}$, y por ello el Estado chileno tenía la obligación de "no restringir su libertad más allá de los límites estrictamente necesarios, pues la prisión preventiva es una medida cautelar y no punitiva ${ }^{51 " .}$

Es por estas razones que la Corte llegó a la convicción de que el Estado de Chile utilizó el aparato judicial penal para restringir ilegítimamente los derechos de libertad personal de los comuneros mapuches. Así, el Estado chileno se valió de presunciones jurídicas ilegales, pruebas reservadas, medidas cautelares arbitrarias y justificaciones antijurídicas para privar arbitrariamente de la libertad de los comuneros mapuches; lo que trajo consigo la vulneración del principio de presunción de inocencia por el año y tres meses que, por ejemplo, Pichún y Norín estuvieron en prisión preventiva ${ }^{52}$, criminalizando las legítimas prerrogativas mapuches mediante la prisión preventiva de sus líderes.

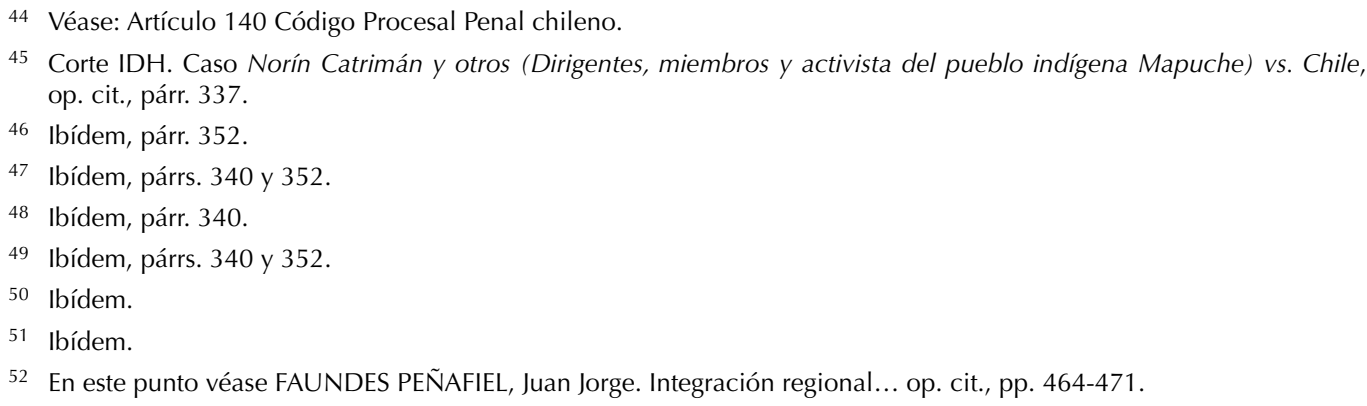




\section{Violación a la libertad de pensamiento, de expresión, y de derechos políticos}

Todas las vulneraciones ilegítimas expuestas que caracterizaron el procedimiento penal contra los comuneros mapuches, consecuencialmente tiñen el fondo del asunto de violaciones a los derechos humanos, consagrándose la criminalización de la protesta de las demandas mapuches por el Estado chileno.

La Corte IDH condenó al Estado chileno por la violación a la libertad de pensamiento y expresión en virtud de las sentencias condenatorias que vulneraron el principio de legalidad y normas procesales, además de, según la Corte, violar el principio de proporcionalidad de la pena ${ }^{53}$. Su argumento es que la inhabilitación de quince años "para explotar un medio de comunicación social o ser director o administrador del mismo, o para desempeñar en él funciones relacionadas con la emisión o difusión de opiniones o informaciones ${ }^{54 "}$ corresponde a una pena desproporcional al bien jurídico afectado y a la culpabilidad con la que actuaron los actores. La judicatura chilena no entendió el rol de líderes políticos y espirituales que les correspondía a Norín Catrimán, Huetequeo Pichún y Ancalaf Llaupe, por lo que la pena recién expuesta "ha restringido la posibilidad de participar en la difusión de opiniones, ideas e información a través del desempeño de funciones en medios de comunicación social, lo cual podría limitar el ámbito de acción de su derecho a la libertad de pensamiento y expresión en el ejercicio de sus funciones como líderes o representantes de su comunidad ${ }^{55}$ ". Además, considera la Corte IDH, que la sentencia penal en contra de los comuneros mapuches, podría producir "un efecto intimidante e inhibidor para el ejercicio de la libertad de expresión, derivado de los particulares efectos que tuvo la aplicación indebida de la Ley Antiterrorista del Pueblo Mapuche ${ }^{56 ", ~ p u d i e n d o ~ c o n l l e v a r ~ " l a ~ a u t o c e n s u r a ~}$ tanto a quien le es impuesta la sanción como a otros miembros de la sociedad ${ }^{57}$ ". En definitiva, el Estado chileno a través de sentencias penales condenatorias cortó los dispositivos comunicativos que tiene cualquier ciudadano para influir políticamente en democracia ${ }^{58}$, coartando las libertades de expresión y opinión de los líderes de toda una etnia.

Por otro lado, las penas accesorias que el Estado chileno asignó a los involucrados mapuches, como la prohibición al derecho a sufragio, de participación en la dirección de asuntos públicos y acceso a funciones públicas perpetuamente o por un término fijo de 15 años es una condena desproporcional ${ }^{59}$. Ello debido a que -entiende la Corte- afecta la representación de los intereses de sus comunidades respecto de la sociedad chilena. De ese modo, impedir que Ancalaf Llaupe, Norín Catrimán y Pichún Paillalao puedan "participar o dirigir funciones públicas en entidades estatales que, por su propia naturaleza, buscan promover, coordinar y ejecutar acciones de desarrollo y protección de las comunidades indígenas que estos representaban" corresponde a una violación a los derechos amparados en el artículo 23 de la $\mathrm{CADH}$.

53 Corte IDH. Caso Norín Catrimán y otros (Dirigentes, miembros y activista del pueblo indígena Mapuche) vs. Chile, op. cit., párr. 374.

54 Ibídem.

55 Ibídem, párr. 373.

56 Ibídem, párr. 376.

57 Ibídem.

58 HABERMAS, Jürgen. Facticidad... op. cit. pp. 250-252.

59 Corte IDH. Caso Norín Catrimán y otros (Dirigentes, miembros y activista del pueblo indígena Mapuche) vs. Chile, op. cit., párr. 376. 
Así la criminalización de la protesta no está solo en la "persecución criminal de aquellos repertorios de acción de las movilizaciones indígenas que se han considerado constitutivos de delito ${ }^{60 "}$, sino además en los tapones que el Estado chileno ha impuesto al discurso político mapuche, impidiendo su desenvolvimiento fluido en democracia, que como se ha dicho, permite el repensar y replantear la legitimidad del ordenamiento jurídico.

\section{Reparaciones del Estado de Chile a las víctimas}

La Corte IDH dictaminó medidas de restitución, rehabilitación, satisfacción y garantías de no repetición para con las víctimas. En las medidas de restitución estas comprendieron: i) dejar sin efecto la declaración de las ocho víctimas como autores de delitos de carácter terrorista; ii) dejar sin efecto las penas privativas de libertad y penas accesorias y iii) disponer la libertad personal de las víctimas que aún se encuentren sujetas a libertad condicional ${ }^{61}$. Junto con ello las medidas de rehabilitación contemplaron las que el Estado chileno debe brindar gratuitamente tratamientos médicos, psicológicos y/o psiquiátricos de forma inmediata a cada una de las víctimas ${ }^{62}$. Las medidas de reparación fueron, y a pesar de que los litigantes propusieron "un reconocimiento público de responsabilidad" y "pedido público de disculpas ${ }^{63 "}$, solo la publicación y publicidad del fallo en comento, y el otorgamiento de becas a los hijos de las víctimas, debido a la ausencia por el sometimiento de la prisión de las víctimas que impidió una manutención y cuidado de sus familias, afectando la posibilidad de que sus hijos accedieran o completaran sus estudios ${ }^{64}$.

Por último, las garantías de no repetición tuvieron como consecuencia la obligación del Estado de Chile en adecuar su ordenamiento jurídico interno, en cuanto al derecho de la defensa a interrogar a testigos protegidos y adecuar su normativa al artículo 8.2f de la CADH. Cabe decir que uno de los dispositivos procesales para vulnerar el debido proceso de las víctimas, y criminalizar la protesta, fue utilizar testigos protegidos para fundamentar condenas, sin controles judiciales efectivos $^{65}$. Esto implica una inseguridad jurídica ${ }^{66}$ que puede eventualmente volverse a utilizar para vulnerar el debido proceso y criminalizar disidencia política en Chile. Es por ello que la Corte IDH le ordenó al Estado chileno que "regule con claridad y seguridad la medida procesal de protección de testigos relativa a la reserva de identidad, asegurando que se trate de una medida excepcional, sujeta a control judicial en base a los principios de necesidad y proporcionalidad, y que ese medio de prueba no sea utilizado en gravo decisivo para fundar una condena, así como regular las correspondientes medidas de contrapeso que aseguren que la afectación al derecho de defensa sea suficientemente contrarrestada67". Con ello poder evitar que nuevamente, por medio de dispositivos procesales, se vuelva a criminalizar la protesta en Chile por su aparato judicial y de persecución criminal.

60 FAUNDES PEÑAFIEL, Juan Jorge. Integración regional... op. cit. 434.

61 Corte IDH. Caso Norín Catrimán y otros (Dirigentes, miembros y activista del pueblo indígena Mapuche) vs. Chile, op. cit., párr. 422.

62 Ibídem, párr. 425.

63 Ibídem, párr. 430.

64 Ibídem, párr. 432.

65 Ibídem, párr. 435.

66 Ibídem, párr. 436.

67 Ibídem. 


\section{Conclusión}

Las violaciones a derechos humanos cometidas por Chile criminalizan las reivindicaciones sociales que el Pueblo Mapuche mantiene contra dicho Estado, atentando no solo contra los derechos de cada una de las víctimas, sino también contra la democracia interna del territorio chileno en los términos habermasianos expuestos precedentemente.

La criminalización de la protesta mapuche se materializó mediante tres canales:

i) En la vinculación de las demandas mapuches a movimientos violentos y/o terroristas, sometiendo a los comuneros mapuches a juicios contrarios al principio presunción de inocencia a través de la aplicación de Ley Antiterrorista.

ii) En la utilización del monopolio de la persecución penal para deslegitimar discursos políticos mapuches por medio de la investigación de delitos de terrorismo, no justificando su privación de libertad ni sus detenciones, vulnerando el principio de inocencia y;

iii) En la restricción de sus derechos de libertad de expresión y pensamiento mediante sentencias penales arbitrarias y desproporcionales, coartando -además- sus derechos políticos por reivindicar demandas históricas y del todo legítimas en un Estado democrático.

Se concluye que solo respetando los derechos de libertad de expresión, de pensamiento y los derechos políticos, pueden mantenerse las condiciones comunicativas necesarias para que fuentes espontáneas de vindicaciones sociales (como la mapuche) puedan permearse en los discursos políticos (y legislativos) de las instituciones estatales; y con ello pueden darse las condiciones necesarias para que un Estado sea realmente democrático ${ }^{68}$. Al comprobarse la violación flagrante de derechos humanos del Estado de Chile contra los comuneros mapuches por actos que pretenden reivindicar demandas sociales, el Estado chileno quebró la legitimidad en su soberanía, no solo por violar los derechos fundamentales de sus habitantes, sino también por llevar a la cárcel a activistas políticos impidiendo discursos legítimos que provienen de demandas históricas del Pueblo Mapuche.

68 HABERMAS, Jürgen Facticidad... op. cit., p. 252. 